\title{
The generalization of some results for Bernstein and Stancu operators
}

\section{DAN MiClĂUŞ and PETRU I. BRAICA}

\section{ABSTRACT.}

In the present paper we generalize some results for Bernstein and Stancu operators. Firstly, we establish a relationship between two results concerning calculation of test functions by Bernstein operators. Secondly, using this relationship and some known results we prove in every case a Voronovskaja type theorem, the uniform convergence and the order of approximation for Bernstein and Stancu operators.

Department of MATHEMATiCs AND COMPUTER SCIENCE

NORTH UNIVERSITY OF BAIA MARE

VictORIEI 76, 430122 BAIA MARE, ROMANIA

E-mail address: danmiclausrz@yahoo.com

SECONDARY SCHOOL "GRIgORE MOISIL"

Mileniului 1, 440037 SATU Mare, Romania

E-mail address: petrubreyahoo.com

Received: 26.02.2011; In revised form: 28.09.2011; Accepted: 30.09.2011.

2010 Mathematics Subject Classification. 41A10, 41A25, 41A36.

Key words and phrases. Bernstein operators, Stancu operators, falling factorials, Pochhammer symbol, Stirling numbers of second kind, Voronovskaja type theorem, modulus of continuity, order of approximation. 